\title{
Las mujeres desean que se les brinde información sobre la problemática del sobrediagnóstico cuando se enfrentan al rastreo de cáncer mamario
}

Women wants information about overdiagnosis when facing breast cancer screening

Hersch J y col. BMJ 2013;346:f158. doi: 10.1136/bmj.f158.

\section{Objetivos}

Evaluar cómo la información y el conocimiento acerca del sobrediagnóstico puede influenciar actitudes y conductas de las mujeres hacia el rastreo de cáncer de mama (CM) mediante mamografía.

\section{Diseño, lugar y población}

Estudio cualitativo llevado a cabo durante 2011. Participaron mujeres de 40 a 79 años con manejo fluido del inglés y sin diagnóstico previo de $\mathrm{CM}$, que habían sido identificadas en forma aleatoria en el directorio telefónico de los suburbios de Sídney, Australia.

\section{Métodos}

Se realizaron grupos focales que incluyeron cuatro a nueve personas cada uno, para explorar cómo integraban sus actuales conocimientos sobre el rastreo de CM con información nueva acerca de los conceptos de sobrediagnóstico, consultándose a las mujeres sobre su intención personal de rastreo (no sobre la política nacional de rastreo). En cada sesión, se incluyó una presentación explicando el concepto de sobrediagnóstico (el diagnóstico de una condición que no habría causado síntomas ni daño si no hubiera sido detectada), y las tasas reportadas en la bibliografía (1 a 50\%). Asimismo, se les brindó información sobre los beneficios del rastreo en la mortalidad, conduciéndose a continuación discusiones grupales guiadas. Al final de cada sesión se aplicó un cuestionario para evaluar la compresión de las mujeres sobre los puntos claves discutidos.

\section{Resultados}

De 188 mujeres elegibles, 78 (66\%) accedieron a participar en los grupos focales, continuándose la conformación de los grupos hasta alcanzarse la saturación temática (redundancia de los datos), lo que terminó incluyendo un total de 50 mujeres con distinto nivel educativo, divididas en ocho grupos focales. El $24 \%$ fueron menores de 50 años y el $14 \%$ de las mayores de 50 años nunca había realizado mamografía como rastreo. Las mujeres valoraban el rastreo como un reaseguro, mientras que su conocimiento previo acerca de la problemática del sobre-diagnóstico era mínimo. Sin embargo, la mayoría pareció haberla comprendido $(60 \%$ de compresión total y $24 \%$ de parcial) luego de las sesiones. La intención personal de continuar realizando rastreo de $\mathrm{CM}$ fue dependiente de la tasa de sobre-diagnóstico que se les informara a las participantes: algunas manifestaron la necesidad de realizar una decisión más cautelosa ante escenarios que involucraran tasas de $50 \%$, mientras que las tasas intermedias (30\%) y las bajas (1 a $10 \%$ ) tuvieron poco impacto en las actitudes y la intención de rastreo. La mayoría manifestó la importancia de incluir esta información para tomar decisiones informadas; y muchas, igualmente continuaban queriendo ser estimuladas para realizarse el rastreo. En algunas mujeres, la información acerca de sobrediagnóstico no cambió tanto su actitud sobre el rastreo, sino sobre lo que pensaban que podría ser su conducta posterior en caso de un resultado positivo: tratamiento estándar vs alternativo (seguimiento controlado o "watchful waiting" y terapias no probadas). También surgió como inquietud, que en las mujeres tratadas por $\mathrm{CM}$, el conocimiento acerca de la problemática del sobrediagnóstico podría hacer más dificultoso sobrellevar los efectos adversos de los tratamientos, teniendo en cuenta que ellas tendrían claro que podrían ser innecesarios. Por otro lado, a algunas mujeres les preocupó la idea de que la discusión acerca de sobrediagnóstico formara parte de una agenda del gobierno para recortar fondos para el rastreo.

\section{Conclusión}

El sobrediagnóstico no fue un concepto familiar para las mujeres de este estudio. Sin embargo, la mayoría pudo entenderlo luego de las sesiones de discusión. La magnitud del sobrediagnóstico importa y muchas mujeres expresaron su deseo de que la información estuviese disponible a la hora de discutir sobre el rastreo o bien comprender sus pros y contras, para luego ser asistidas en la decisión personal.

Fuente de financiamiento: Informed Medical Decisions Foundation y National Health and Medical Research Council of Australia.

\section{Comentario}

El sobrediagnóstico y su consecuencia, el tratamiento innecesario, son considerados uno de los efectos adversos más importantes del rastreo de cáncer ${ }^{1-2}$. Vale destacar que si bien la intención individual de rastreo varió dependiendo de la magnitud del sobrediagnóstico y del balance entre los riesgos y los beneficios, la mayoría de las participantes coincidió en que sería importante que esta información estuviese disponible para tomar una decisión informada ${ }^{3}$.

Dado que las campañas se enfocan mayormente en los efectos positivos del rastreo, esta información podría cambiar las actitudes de la población hacia esta práctica e incluso influir en el tipo de terapia a usar ante un eventual resultado positivo ${ }^{4}$. La muestra estudiada de mujeres provenientes de los suburbios de Sídney puede que no refleje las ideas y visiones de otras poblaciones, por lo que es recomendable ser cautelosos para extrapolar los resultados. Por otro lado, no se discutieron otros resultados posibles del rastreo (como falsos positivos y negativos) para no abrumar con información. Sin embargo, estos datos podrían haber cambiado los resultados del estudio.

\section{Conclusiones del comentador}

Teniendo en cuenta la importancia que por años se le ha dado a la prevención y al rastreo, el concepto de sobrediagnóstico puede resultar anti-intuitivo y generar resistencias, factor a tener en cuenta a la hora de establecer estrategias de comunicación. Consideramos importante continuar estudiando las visiones de las mujeres sobre el rastreo, evitando basar las políticas de salud en presunciones, y proveyéndoles información suficiente para facilitar sus decisiones informadas.

María Victoria Salgado [ Servicio de Medicina Familiar y Comunitaria del Hospital Italiano de Buenos Aires maria.salgado@ hiba.org.ar ]

Salgado M. Las mujeres desean que se les brinde información sobre la problemática del sobrediagnóstico cuando se enfrentan al rastreo de cáncer mamario. Evid Act Práct Ambul. 2014, 17(2). Abr-Jun. 63. Comentado de: Hersch J y col. Women's views on overdiagnosis in breast cancer screening: a qualitative study. BMJ. 2013;346:f158. doi: 10.1136/bmj.f158. PMID: 23344309.

\section{Referencias}

1. Welch $\mathrm{H}$ y col. Overdiagnosis in cancer. J Natl Cancer Inst 2010;102:605-13.

2. Jorgensen K y col. Who evaluates public health programmes? A review of the NHS Breast Screening Programme J y col. Soc Med2010;103:14-20.

3. Welch $\mathrm{H}$ y col. Overdiagnosis and mammography screening. BMJ2009;339:b14

4. Jorgensen K y col. Content of invitations for publicly funded screening mammography.BMJ2006;332:538-41 